\title{
TAILORING MIL-STD-461B FOR NAVAL AVIONICS APPLICATIONS
}

\author{
Robert G. Siefker
}

\begin{abstract}
Naval aviation electronics (Avionics) systems are specified and procured using MIL-STD-461 to set the fundamental EMI requirements. MIL-STD-461 permits and encourages "tailoring" the EMI specifications for each equipment to the anticipated usage.

In this paper, the Naval Avionics Center Staff Engineer for Electromagnetic Effects presents a typical tailored EMI specification as used within the Naval Air Systems Command to procure carrier based aircraft avionics. Included are the rationale for and the explanation of each modification and an estimate of the electromagnetic environment found aboard the US Navy Aircraft carriers.
\end{abstract}

Mil-STD-461B Part 1 states that the standards set forth "may be tailored by the procuring activity." This simple statement recognizes the unique applications of many equipments and the wide variety of electromagnetic environments (EMEs) in which modern military electronics is required to operate. However, tailoring a military standard such as MIL-STD-461B is sometimes easier said than done.

In 1982, the Naval Avionics Center carefuly reviewed the requirements of MIL-STD-461B and concurrently studied the EME of today's Navy ships and stations. A detailed review of each applicable section of MIL-STD-461B was made and an extensively tailored specification was formulated. This tailored specification has formed the basis for several EMI specifications for avionics systems including airborne communications, electronic warfare and interior communications systems. This paper reports the product of that tailoring effort. While the focus of this paper is on Parts 1 and 2 of MIL-STD-461B, the concepts are directly applicable to the remaining eight parts.

The sample specification shown in Figure 1 represents no particular system but rather is a composite example. The

Based on a presentation to the 1987 IEEE

Electromagnetic Compatibility Meeting.

U.S. Government work not protected by U.S. copyright organizational method employed in this sample is that of MIL-STD-961A. It is worth emphasizing that in several cases modified limits are shown merely as examples of how to properly modify limits and are not intended to represent a "new standard" for Naval Avionics applications. An explanation of each paragraph of Figure 1 follows and is presented simply in the order encountered in Figure 1, not necessarily in order of significance.

The applicable documents section (paragraph 2.0) of procurement specifications is often overlooked but forms a cornerstone upon which the entire EMI specification rests. Paragraph 2.1 must contain those documents later referenced in the specification.

The detailed requirements section (paragraph 3.0) forms the heart of any specification. In paragraph 3, all detailed performance requirements are stated. In Figure 1, the detailed EMI requirements are arbitrarily shown as paragraph 3.3.17. (Throughout this paper, paragraph references shall be those of Figure 1.)

The general statement of 3.3.17 may seem obvious, but must be explicitly stated in order to be enforceable. The closing sentence "These requirements shall be met in all operating modes." eliminates any ambiguity of intent.

A seemingly trivial (but nonetheless important) change is that of 3.3.17.1. Here the Naval Air Systems Command EMI design guide is inserted in place of other guides which may not adequately address NAVAIR problems.

The next few paragraphs of Figure 1 reflect the standard specifications of MIL-STD-461B and are used to relax or stiffen the standard limits as appropriate. A few examples are shown in Figure 1. These examples are given for illustration purposes only and do not represent recommended revised standards. Note that each separate requirement is assigned a subparagraph number. This practice takes a little more space, but is far more convenient to revise or change. Table 2-II (or the corresponding table in other parts) of MIL-STD-461B should be used to establish applicability of EMI requirements.

Modification of standard limits has a few pitfalls which should be carefully avoided. One is a change of emission 
limits without specifying whether the change applies to broadband or narrowband limits or both. Another is the extension of frequency limits without defining emission limits over the extended frequency range. The modifications shown in Figure 1 were arbitrarily chosen to illustrate proper tailoring. Serious consideration must be made before modifications are incorporated. Arbitrary relaxations should be avoided and careful impact analyses should precede all changes in standard limits. On the other hand, excessive performance can add cost and weight to systems, so each separate specification should be examined for appropriateness. Note that the change imposed by 3.3.17.3.2 merely re-imposes the MIL-STD-461A CS02 requirements for grounds and neutrals. This particular change is recommended for all Naval Avionics applications.

Perhaps the one specification area which most confuses EMI specification writers is the tailoring of $\mathrm{RSO3}$ field levels. The RS03 modification of Figure 1 has evolved over a 4-year period and yet addresses the difficult Navy electromagnetic environment (EME), yet recognizes the cost impact of test requirements above $200 \mathrm{v} / \mathrm{m}$.

The EME of Table 3.1 is specified for use by the supplier in all analyses and design considerations. In addition, the Navy reserves the right to perform tests at these levels. The modulation formats of Tables 3.1, 3.2, and 3.3 are not associated with any particular emitters, but instead are selected to be representative of the Navy EME. The high level RS03 test requirements are given in Table 3.2 of Figure 1. The levels of Table 3.2 are limited to $10.6 \mathrm{~mW} / \mathrm{cm}^{2}$ or $200 \mathrm{v} / \mathrm{m}$ in recognition that higher test levels frequently drive the cost of testing rapidly upward. Also, if equipment is properly designed using Table 3.1 and then successfully tested to the levels of Tables 3.2 and 3.3, it will probably survive tests at the levels of Table 3.1 or higher with few problems. Note that Tables 3.1 and 3.2 contain Scan and Dwell entries. These simulate the rotation of high gain radar antennas which expose the equipment to the higher levels for a short period of time (dwell) every few seconds (scan). The EME of Table 3.3 on the other hand represents the backlobe and sidelobe levels from these antennas and consequently contains no such entries.

An area frequently addressed poorly or even totally overlooked in EMI specifications is the definition of susceptibility. The definitions given in 3.3.17.4 are typical of those recommended for use. Often, the EMC engineer is not the best person to draft this section but should rely on guidance from the program manager to the acceptable level of degradation in the presence of the various EME. It is seldom appropriate to define susceptibility as "any evidence of the susceptibility signal" since the "evidence" may be truly incidental to system operation. The susceptibility definition should be a reasonable reflection of permissable system performance levels and should be objectively determinable. Note that two or more definitions of susceptibility may be used. Figure 1 shows two definitions of susceptibility under varying conditions, but more might be appropriate.

Figure 1 addresses non MIL-STD-461 EMI specification paragraphs beginning with 3.3.17.5. These paragraphs illustrate that additions to the standard specifications are certainly within the scope of tailoring. The ground plane inter- ference test of 3.3.17.5 is intended to determine how the system will behave if electromagnetic "noise" is impressed on the chassis. This can happen if the chassis ground deteriorates due to a broken ground strap or corrosion or simply during exposure to the EME found on Navy aircraft. The grounding and bonding requirements of 3.3.17.6 and its subparagraphs, and 3.3.17.7 both establish safety requirements and impose good EMC design practices. The requirements of 3.3.17.8 help control corrosion, one of the Navy's most serious problems. Specification additions need not be simple one paragraph changes. In one case, a receiver specification was being prepared specified and the old MILSTD-461A CS08 requirement was deemed appropriate. A section was added to the specification called "Single Signal Spurious Response" which simply used the wording from MIL-STD-461A for the CS08 requirement.

Another serious pitfall to be avoided is dual specification. When a specification contains two or more conflicting requirements, the supplier is free to choose the easier and ignore the more difficult requirement. Blanket application of MIL-STD-461 can and often does result in unintentional dual specification. For example, let us assume that a transmitter specification contains a stringent spurious output paragraph in one section and elsewhere requires compliance with MILSTD-461. The CE06 requirement then will unintentionally form a dual specification and could negate the intended stringent requirement. This can be avoided only by carefully reviewing the specification for conflict and then modifying the appropriate EMI subparagraph by adding words such as "except as modified by 3.4.9.1" (where 3.4.9.1 represents the desired performance).

The remainder of Figure 1 deals with paragraph 4 of the specification which provides quality assurance requirements and should be complimentary to paragraph 3 . Each requirement of paragraph 3 should be reflected by a quality assurance provision of paragraph 4 . At the present time an anomaly exists between MIL-STD-461, which has been extensively revised and MIL-STD-462 in which corresponding changes are pending. These anomalies are addressed by paragraph 4.3.4 and its subparagraphs in Figure 1. These paragraphs may seem obvious and trival, but a specification is no place for implications. A specification should explicitly state all desired system requirements, leaving as little as possible for interpretation. Paragraph 4.3.4.5 of Figure 1 presents an example of how MIL-STD -462 methodology can be tailored or changed. In this case, a modification of the CSO3 test method is required. The rationale behind this change is addressed in a companion paper and will not be discussed here.

The proper tailoring of MIL-STD-461 can be complex and time consuming the first time it is done. Once done for the first project however, future tailoring can be accomplished in a fraction of the time by using the results from the first effort as a starting point. In addition to setting forth unambiguous detailed requirements, a well tailored EMI specification also serves to send a signal to prospective suppliers that EMI control is an important part of the program. The combination will result in electromagnetic compatibility during aircraft integration. And that, after all, is the "name of the game", 


\section{Figure 1}

\section{Sample EMI Specification}

2.1 Applicable Documents - Government

AD-1115 ELECTROMAGNETIC COMPATIBILITY DESIGN
GUIDE FOR AVIONICS AND RELATED GROUND SUPPORT EQUIPMENT

MIL-STD-461 ELECTROMAGNETIC EMISSION AND SUSCEPTIBILITY REQUIREMENTS FOR THE CONTROL OF ELECTROMAGNETIC INTERFERENCE

MIL-STD-462 ELECTROMAGNETIC INTERFERENCE CHARACTERISTICS, MEASUREMENT OF

3.3.17 ELECTROMAGNETIC INTERFERENCE (EMI) - The unit shall comply with the requirements of MIL-STD-461 for Class Alb equipment except as modified by this specification. These requirements shall be met in all operating modes.

3.3.17.1 DESIGN GUIDELINES - MIL-STD-461, Part 1, paragraph 4.3 is modified by the following additions and deletions:

$\begin{array}{ll}\text { Add: } & \text { NAVAIR AD-1115 } \\ \text { Delete: } & \text { AFSC DH 2-5 } \\ & \text { AFSC DH 2-7 } \\ & \text { AMC Pamphlet 706,235 } \\ & \text { NAVELEX 01001,106 }\end{array}$

3.3.17.2 EMISSION LIMITS - The following MIL-STD-461, Part 2 limits apply as modified.

\subsection{CE01}

3.3.17.2.2 CE03 except that the narrowband limit shall be $30 \mathrm{dBua}$ from $920 \mathrm{kHz}$ (approximately) to $500 \mathrm{MHz}$

3.3.17.2.3 CE06 except that the broadband limit for receivers shall be $30 \mathrm{dBuV} / \mathrm{MHz}$

3.3.17.2.4 $\mathrm{CEO}$

3.3.17.2.5 RE01

3.3.17.2.6 RE02 except that the narrowband upper frequency limit shall be $18 \mathrm{GHz}$. The narrowband limit from $10 \mathrm{GHz}$ to $18 \mathrm{GHz}$ shall be derived by straight line extrapolation of Figure 2-9 of MIL-STD-461B.

3.3.17.3 SUSCEPTIBILITY LIMITS - The following MIL-STD-461, Part 2 limits apply as modified:

3.3.17.3.1 CSO1

3.3.17.3.2 CSO2 except that this requirement shall apply to all neutrals and grounds whether or not they are internally returned to chassis ground.

3.3.17.3.3 CSO3 except that the upper frequency limit shall be as specified in 4.3.4.5

3.3.17.3.4 CSO4

3.3.17.3.5 CS05 except that the upper frequency limit shall be $1 \mathrm{GHz}$

3.3.17.3.6 CSO6

3.3.17.3.7 RS01

3.3.17.3.8 RSO2

3.3.17.3.9 RS03 - The field levels and modulations shall be as specified in Table 3.1, RS03 Signals, Design and Analysis, Table 3.2, High Level RS03 Signals, Test Levels, and Table 3.3, RS03 Signals, Continuous Application Test Levels. Table 3.1 shall be used for all design and analysis calculations. Tables 3.2 and 3.3 shall be used for actual RS03 testing. The procuring agency reserves the right to perform $\mathrm{RSO}_{3}$ testing at the levels of Table 3.1 as reduced by 3.3.17.3.9.1. The susceptibility criteria of 3.3.17.4.1 does not apply during application of Table 3.2 levels.

3.3.17.3.9.1 AIRFRAME SHIELDING - The levels of Tables 3.1 and 3.3 may be reduced by $20 \mathrm{~dB}$ from $14 \mathrm{kHz}$ through $20 \mathrm{MHz}$ and $30 \mathrm{~dB}$ from $100 \mathrm{MHz}$ and higher except that the levels of Table 3.1 shall not be reduced below $10.6 \mathrm{mw} / \mathrm{cm}^{2}(200 \mathrm{~V} / \mathrm{m})$ and the levels of Table 3.3 shall not be reduced below $0.106 \mathrm{mw} / \mathrm{cm}^{2}(20 \mathrm{~V} / \mathrm{m})$. The levels of Table 3.2 shall not be reduced.

3.3.17.4 SUSCEPTIBILITY DEFINITION - The following criteria shall be applied to determine whether the unit is susceptible:

3.3.17.4.1 RECEIVE MODE - The unit shall be considered susceptible if, during application of any susceptibility signal (including requirement 3.3.17.5), the output signal plus noise to noise ratio of the receiver, with a standard input (as defined in 3.2.10) degrades by greater than $6 \mathrm{~dB}$ from that measured without the susceptibility signal applied.

3.3.17.4.2 TRANSMIT MODE - The system shall be considered susceptible if, during application of any susceptibility signal (including requirement 3.3.17.5), the transmitter carrier to noise ratio fails to comply with 3.2.6.1 or if the carrier incidental FM fails to comply with 3.2.6.2.

3.3.17.4.3 Any repeatable non-command change in the modes of operation frequency, control settings, etc., of the unit shall be considered an indication of susceptibility. This shall apply whether the change is transient (momentary) or non-transient (permanent) in nature. In addition the inability to change modes of operation frequency, control settings, etc., while exposed to the susceptibility signal shall be considered indication of susceptibility.

3.3.17.4.4 TALK THROUGH - In addition, the unit shall demonstrate the ability to receive clear voice in both AM and FM modes during susceptibility and ground plane interference tests. This talk through test shall be performed using an RF input of 20 microvolts or less.

3.3.17.5 GROUND PLANE INTERFERENCE - The unit shall be capable of specified performance when subjected to the following aircraft chassis noise between the interfacing WRAs:

1. Three volts RMS from $320 \mathrm{~Hz}$ to $500 \mathrm{~Hz}$. (1)

2. One volt RMS from $500 \mathrm{~Hz}$ to $20 \mathrm{MHz}$. (2)

3. +/- eight volt pulses, 70 usec wide at 100 pps. (3)

(1) Not to exceed $150 \mathrm{~mA}$ RMS applied current.

(2) Not to exceed 150ma RMS applied current for frequencies between $500 \mathrm{~Hz}$ and $50 \mathrm{kHz}$. Not to exceed 1 watt $(\mathrm{CW})$ from a $50-\mathrm{ohm}$ source for frequencies above $50 \mathrm{kHz}$.

(3) Not to exceed 15a peak current spikes.

3.3.17.6 GROUNDING REQUIREMENTS - The grounding system between WRAs of the equipment shall be compatible and consistent with the following aircraft grounding scheme. All WRA's shall be grounded in such a manner as to prevent ground loops and common ground returns for signal and power circuits, provide effective shielding for signal circuits, minimize EMI, and to protect personnel from electrical hazards.

3.3.17.6.1 CHASSIS GROUNDS - A ground wire of minimum length connected internally to the WRA chassis shall be provided at a pin on each primary power connector. No circuit shall be allowed to utilize this wire as it's primary return.

3.3.17.6.2 SHIELDING GROUNDING - A separate connector pin shall be provided for each aircraft wire shield unless suitable grounding is provided in external cable backshells. The connector shield pins shall be grounded to the equipment chassis inside the WRA adjacent to the connector mounting by the shortest means practical.

3.3.17.6.3 COMPONENT GROUNDS - All externally exposed metal parts, shields, control shafts, switch handles, connectors, bushings, etc., shall be grounded to the chassis.

3.3.17.7 BONDING - A means of electrically bonding the equipment to the aircraft chassis shall be provided and shall comply with the requirements of MIL-B-5087. Bonding resistance between the bonding surface and all parts of the equipment case shall not exceed 2.5 milliohms.

3.3.17.8 SHIELDING GASKETS - Shielding gaskets and similar devices for RF applications shall avoid the use of materials which represent severe dissimilar metal combinations with the interface.

4.3.4 ELECTROMAGNETIC INTERFERENCE (EMI) TESTS - Compliance with the requirements of 3.3.17 and its subparagraphs shall be demonstrated by tests. These tests shall be performed in accordance with MIL-STD-462 as modified by this paragraph.

4.3.4.1 EMI TEST PLAN - The supplier shall perform EMI tests in accordance with an approved EMI Test Plan. Said Test Plan shall describe all EMI tests required to demonstrate compliance with the requirements of 3.3.17 and shall address all anomalies, inconsistencies, and omissions (if any). Said Test Plan shall detail a combination of operating modes to be tested. Said Test Plan must be approved by the procuring agency prior to the commencement of EMI testing.

4.3.4.2 CE01 TEST PROCEDURES - The requirements of 3.3.17.2.1 shall be demonstrated using MIL-STD-462 Notice 2 Test Method CE01 
for all power leads and MIL-STD-462 Notice 2 Test Method CE02 for all control and signal leads.

4.3.4.3 CE03 TEST PROCEDURES - The procedures of 3.3.17.2.2 shall be demonstrated using MIL-STD-462 Notice 2 Test Method CE03 for all power leads and MIL-STD-462 Notice Test Method CE04 for all control and signal leads tested.

4.3.4.4 CE07 TEST PROCEDURE - The supplier shall devise a test to demonstrate compliance with the requirements of 3.3.17.2.4. This test shall be included as a part of the EMI Test Plan.

4.2.4.5 CS03 TEST PROCEDURE - The requirements of 3.3.17.3.3 shall be demonstrated by using MIL-STD-462 Test Method CS03 except that paragraphs $5 . \mathrm{g}$ and $5 . \mathrm{j}$ shall be replaced with the following:

(g) Generator 2 shall be initially set at a frequency that is $\mathrm{df}$ above $\mathrm{f1}$ with an output equal to the applicable limit (specified in MIL-STD-461) above the level obtained in step (d). Slowly increase the frequency of both generator 1 and generator 2 at rates such that the formula $2 \mathrm{f} 1-\mathrm{f} 2=\mathrm{fo}$ is satisfied, while maintaining a constant output level, until a frequency fu, as defined below, is reached by generator 2 . If a synthesized generator is used, the step size selected shall be less than $10 \times \mathrm{df}$ for generator 1 , and $20 \times$ df for generator 2

(1) If the receiver has a preselector (bandpass filter before the first mixer), the upper frequency (fu) shall be

$$
\mathrm{fu}=\mathrm{fO}+10 \mathrm{BW}
$$

where BW is the $30 \mathrm{~dB}$ bandwidth of the preselector. The bandwidth of the preselector should be determined by actual test if possible. Manufacturer's data and/or design curves may be substituted if actual test data are not attainable.

(2) If the receiver does not have a preselector (bandpass filter before the first mixer) the upper frequency, fu, shall be 1.5 times the highest tuned frequency of the receiver.

(j) Repeat steps (h) and (i) with signal generator \#1 set at a frequency df below fo and signal generator $22 \mathrm{dF}$ below fo. Slowly decrease the frequency of both generator 1 and generator 2 at rates such that the formula $2 \mathrm{f} 2-\mathrm{f} 1=\mathrm{fo}$ is satisfied while maintaining a constant output level, until a frequency $\mathrm{f} 1$, as defined below, is reached by generator 2. If a synthesized generator is used, the step size selector shall be less than $10 \times \mathrm{df}$ for generator 1 and $20 \times \mathrm{df}$ for generator 2

(1) If the receiver has a preselector (bandpass filter before the mixer, the lower frequency (f1) shall be

$$
\mathrm{f} 1=\mathrm{f0}-10 \mathrm{BW}
$$

where BW is the $30 \mathrm{~dB}$ bandwidth of the preselector. The bandwidth of the preselector should be determined by actual test if possible. Manufacturer's data and/or curves may be substituted if actual test data are not attainable.

(2) If the receiver does not have a preselector (bandpass filter before the first mixer), the lower frequency, $\mathrm{fl}$, shall be 0.5 times the lowest tuned frequency of the receiver.

4.3.4.6 GROUND PLANE INTERFERENCE - The requirements of 3.3.17.5 shall be demonstrated by test using the setup shown in Figure 4.1.

Table 3.1

RS03 Signals

\begin{tabular}{|c|c|c|c|c|c|c|c|c|}
\hline $\begin{array}{l}\text { Frequency } \\
(\mathrm{MHz})^{8}\end{array}$ & & & lation & & $\begin{array}{l}\text { Power } \\
\text { Density } \\
\left(\mathrm{mw} / \mathrm{cm}^{2}\right)^{5}\end{array}$ & $\begin{array}{l}\mathrm{v} / \mathrm{m} \\
(\mathrm{ref})^{6}\end{array}$ & $\begin{array}{l}\text { Scan } \\
\text { Rate } \\
(\mathrm{sec})^{7}\end{array}$ & $\begin{array}{l}\text { Dwell } \\
\text { Time } \\
\text { (msec)? }\end{array}$ \\
\hline $2-30$ & $\mathrm{AM}$ & $90 \%$ & $1 \mathrm{kHz}$ & SINE WAVE & 10.6 & 200 & 0 & CONT \\
\hline $215-225$ & PAM $^{1}$ & 10 usec $^{2}$ & $\mathrm{PW}^{3}$ & $200 \mathrm{pps}^{4}$ & 10.6 & 200 & 4 & 500 \\
\hline $215-225$ & PAM & 200 usec & PW & $200 \mathrm{pps}$ & 10.6 & 200 & 4 & 500 \\
\hline $400-450$ & PAM & 4 usec & PW & $300 \mathrm{pps}$ & 25 & 310 & 4 & 200 \\
\hline $850-940$ & PAM & 2 usec & PW & $1000 \mathrm{pps}$ & 200 & 870 & 5 & 50 \\
\hline $850-940$ & PAM & 125 usec & PW & $300 \mathrm{pps}$ & 200 & 870 & 5 & 50 \\
\hline $1215-1365$ & PAM & 10 usec & PW & $3000 \mathrm{pps}$ & 10.6 & 200 & 5 & 50 \\
\hline $1260-1400$ & PAM & 5 usec & PW & $3000 \mathrm{pps}$ & 25 & 310 & 5 & 50 \\
\hline $2900-3100$ & PAM & 3 usec & PW & $1000 \mathrm{pps}$ & 17500 & 8100 & 5 & 50 \\
\hline $2900-3100$ & PAM & 70 usec & PW & $200 \mathrm{pps}$ & 17500 & 8100 & 5 & 50 \\
\hline $3100-3500$ & PAM & 10 usec & PW & 3000 pps & 50000 & 13700 & 1 & 50 \\
\hline $3100-3500$ & PAM & 50 usec & PW & $3000 \mathrm{pps}$ & 50000 & 13700 & 1 & 50 \\
\hline $3550-3700$ & PAM & 1 usec & PW & $1000 \mathrm{pps}$ & 2500 & 3000 & 5 & 50 \\
\hline $5400-5800$ & PAM & 1 usec & PW & $600 \mathrm{pps}$ & 320 & 1100 & 5 & 50 \\
\hline $9000-9160$ & PAM & 0.5 usec & PW & $1000 \mathrm{pps}$ & 500 & 1375 & 5 & 50 \\
\hline $9300-9400$ & PAM & 0.2 usec & PW & 1000 pps & 40 & 390 & 5 & 50 \\
\hline $13500-14500$ & PAM & 0.2 usec & PW & $50000 \mathrm{pps}$ & 40 & 390 & 0 & CONT \\
\hline $15400-15700$ & PAM & 0.2 usec & PW & $50000 \mathrm{pps}$ & 10.6 & 200 & 0 & CONT \\
\hline $33000-33400$ & PAM & 0.2 usec & PW & $2000 \mathrm{pps}$ & 2500 & 3070 & 0 & CONT \\
\hline
\end{tabular}

Design and Analysis

Notes:

1 - Pulse Amplitude Modulation.

2 - Microseconds.

3 - Pulse Width.

4 - Pulses Per Second.

5 - Peak Power Density for PAM signals is defined as the power density as measured with an average power measuring device if the generator is run $\mathrm{CW}$; i.e., average power density within the pulse envelope

6 - Volts Per Meter equivalent shown for reference only.

7 - Scan and Dwell refer to simulated antenna rotation. The signal shall be disabled except for the specified dwell. The signal shall be periodically enabled for the specified dwell time with the period equal to the specified scan time.

8 - Frequency ranges listed with more than one modulation shall be repeated as necessary to include all different modulation shown. 
Table 3.2

High Level RS03 Signals

Test Levels

\begin{tabular}{|c|c|c|c|c|c|c|c|c|}
\hline $\begin{array}{l}\text { Frequency } \\
(\mathrm{MHz})^{8}\end{array}$ & & & lation & & $\begin{array}{l}\text { Power } \\
\text { Density } \\
\left(\mathrm{mw} / \mathrm{cm}^{2}\right)^{5}\end{array}$ & $\begin{array}{l}\mathrm{v} / \mathrm{m} \\
\text { (ref) }^{6}\end{array}$ & $\begin{array}{l}\text { Scan } \\
\text { Rate } \\
(\mathrm{sec})^{7}\end{array}$ & $\begin{array}{l}\text { Dwell } \\
\text { Time } \\
(\mathrm{msec})^{7}\end{array}$ \\
\hline $2-30$ & AM & $90 \%$ & $1 \mathrm{kHz}$ & SINE WAVE & 0.66 & 50 & 0 & CONT \\
\hline 220 & PAM $^{1}$ & 10 usec $^{2}$ & $\mathrm{PW}^{3}$ & $200 \mathrm{pps}^{4}$ & 10.6 & 200 & 4 & 500 \\
\hline 220 & PAM & 200 usec & PW & $200 \mathrm{pps}$ & 10.6 & 200 & 4 & 500 \\
\hline 425 & PAM & 4 usec & PW & 300 pps & 10.6 & 200 & 4 & 200 \\
\hline 900 & PAM & 2 usec & PW & 1000 pps & 10.6 & 200 & 5 & 50 \\
\hline 900 & PAM & 125 usec & PW & 300 pps & 10.6 & 200 & 5 & 50 \\
\hline 1250 & PAM & 10 usec & PW & 3000 pps & 10.6 & 200 & 5 & 50 \\
\hline 1350 & PAM & 5 usec & PW & 3000 pps & 10.6 & 200 & 5 & 50 \\
\hline 3000 & PAM & 3 usec & PW & $1000 \mathrm{pps}$ & 10.6 & 200 & 5 & 50 \\
\hline 3000 & PAM & 70 usec & PW & 200 pps & 10.6 & 200 & 5 & 50 \\
\hline 3300 & PAM & 10 usec & PW & $3000 \mathrm{pps}$ & 10.6 & 200 & 1 & 50 \\
\hline 3300 & PAM & 50 usec & PW & 3000 pps & 10.6 & 200 & 1 & 50 \\
\hline 3600 & PAM & 1 usec & PW & $1000 \mathrm{pps}$ & 10.6 & 200 & 5 & 50 \\
\hline 5600 & PAM & 1 usec & PW & 600 pps & 10.6 & 200 & 5 & 50 \\
\hline 9100 & PAM & 0.5 usec & PW & $1000 \mathrm{pps}$ & 10.6 & 200 & 5 & 50 \\
\hline 9375 & PAM & 0.2 usec & PW & $1000 \mathrm{pps}$ & 10.6 & 200 & 5 & 50 \\
\hline 13900 & PAM & 0.2 usec & PW & 50000 pps & 10.6 & 200 & 0 & CONT \\
\hline 15500 & PAM & 0.2 usec & PW & $50000 \mathrm{pps}$ & 10.6 & 200 & 0 & CONT \\
\hline 33200 & PAM & 0.2 usec & PW & $2000 \mathrm{pps}$ & 0.106 & 20 & 0 & CONT \\
\hline
\end{tabular}

Notes:

1 - Pulse Amplitude Modulation.

2 - Microseconds.

3 - Pulse Width.

4 - Pulses Per Second.

5 - Peak Power Density for PAM signals is defined as the power density as measured with an average power measuring device if the generator is run $\mathrm{CW}$; i.e., average power density within the pulse envelope.

6 - Volts Per Meter equivalent shown for reference only.

7 - Scan and Dwell refer to simulated antenna rotation. The signal shall be disabled except for the specified dwell. The signal shall be periodically enabled for the specified dwell time with the period equal to the specified scan time.

8 - Frequency ranges listed with more than one modulation shall be repeated as necessary to include all different modulation shown.

9 - The frequencies listed should be taken as approximate. System performance must be demonstrable at any arbitrarily selected frequency within $\pm 5 \%$ of the frequencies listed.

Table 3.3

RS03 Signals

Continuous Application Test Levels

\begin{tabular}{|c|c|c|c|c|c|c|c|}
\hline \multirow{2}{*}{$\begin{array}{l}\text { Frequency } \\
(\mathrm{MHz})\end{array}$} & & & & & \multicolumn{2}{|c|}{$\begin{array}{l}\text { Power Density } \\
\left(\mathrm{mW} / \mathrm{cm}^{2}\right)\end{array}$} & \multirow{2}{*}{$\begin{array}{c}\mathrm{v} / \mathrm{M} \\
\text { (Ref) }^{6}\end{array}$} \\
\hline & \multicolumn{4}{|c|}{ Modulation } & Peak $^{5}$ & Ave & \\
\hline $0.014-850$ & AM & $90 \%$ & $1 \mathrm{kHz}$ & SINE WAVE & - & 0.66 & 50 \\
\hline $215-225$ & PAM $^{1}$ & 20 usec $^{2}$ & $\mathrm{PW}^{3}$ & $200 \mathrm{pps}$ & 0.126 & - & 22 \\
\hline $215-225$ & PAM & 200 usec & PW & $200 \mathrm{pps}$ & 0.126 & - & 22 \\
\hline $400-450$ & PAM & 4 usec & PW & $300 \mathrm{pps}$ & 0.200 & - & 28 \\
\hline $850-940$ & PAM & 10 usec & PW & $1000 \mathrm{pps}$ & 0.316 & - & 35 \\
\hline $850-940$ & PAM & 125 usec & PW & $300 \mathrm{pps}$ & 0.316 & - & 35 \\
\hline $940-1215$ & PAM & 10 usec & PW & $1000 \mathrm{pps}$ & 0.106 & - & 20 \\
\hline $1215-1365$ & PAM & 10 usec & PW & 3000 pps & 0.106 & - & 20 \\
\hline $1365-2900$ & PAM & 1 usec & PW & $1000 \mathrm{pps}$ & 0.160 & - & 25 \\
\hline $2900-3100$ & PAM & 3 usec & PW & $1000 \mathrm{pps}$ & 1.60 & - & 78 \\
\hline $2900-3100$ & PAM & 70 usec & PW & 200 pps & 1.60 & - & 78 \\
\hline $3100-3500$ & PAM & 10 usec & PW & 3000 pps & 3.18 & - & 110 \\
\hline $3100-3500$ & PAM & 50 usec & PW & 3000 pps & 3.18 & - & 110 \\
\hline $3500-9000$ & PAM & 1 usec & PW & $1000 \mathrm{pps}$ & 0.636 & - & 50 \\
\hline $9000-14000$ & PAM & 0.2 usec & PW & $1000 \mathrm{pps}$ & 0.106 & - & 20 \\
\hline $14000-18000$ & PAM & 0.2 usec & PW & 50000 pps & 0.106 & - & 20 \\
\hline
\end{tabular}

Notes:

1 - Pulse Amplitude Modulation.

2 - Microseconds.

3 - Pulse Width.

4 - Pulses Per Second.

5 - Peak Power Density for PAM signals is defined as the power density as measured with an average power measuring device if the generator is run $\mathrm{CW}$; i.e., average power density within the pulse envelope.

6 - Volts Per Meter equivalent shown for reference only.

7 - Frequency ranges listed with more than one modulation shall be repeated as necessary to include all different modulations and/or field strength shown. 


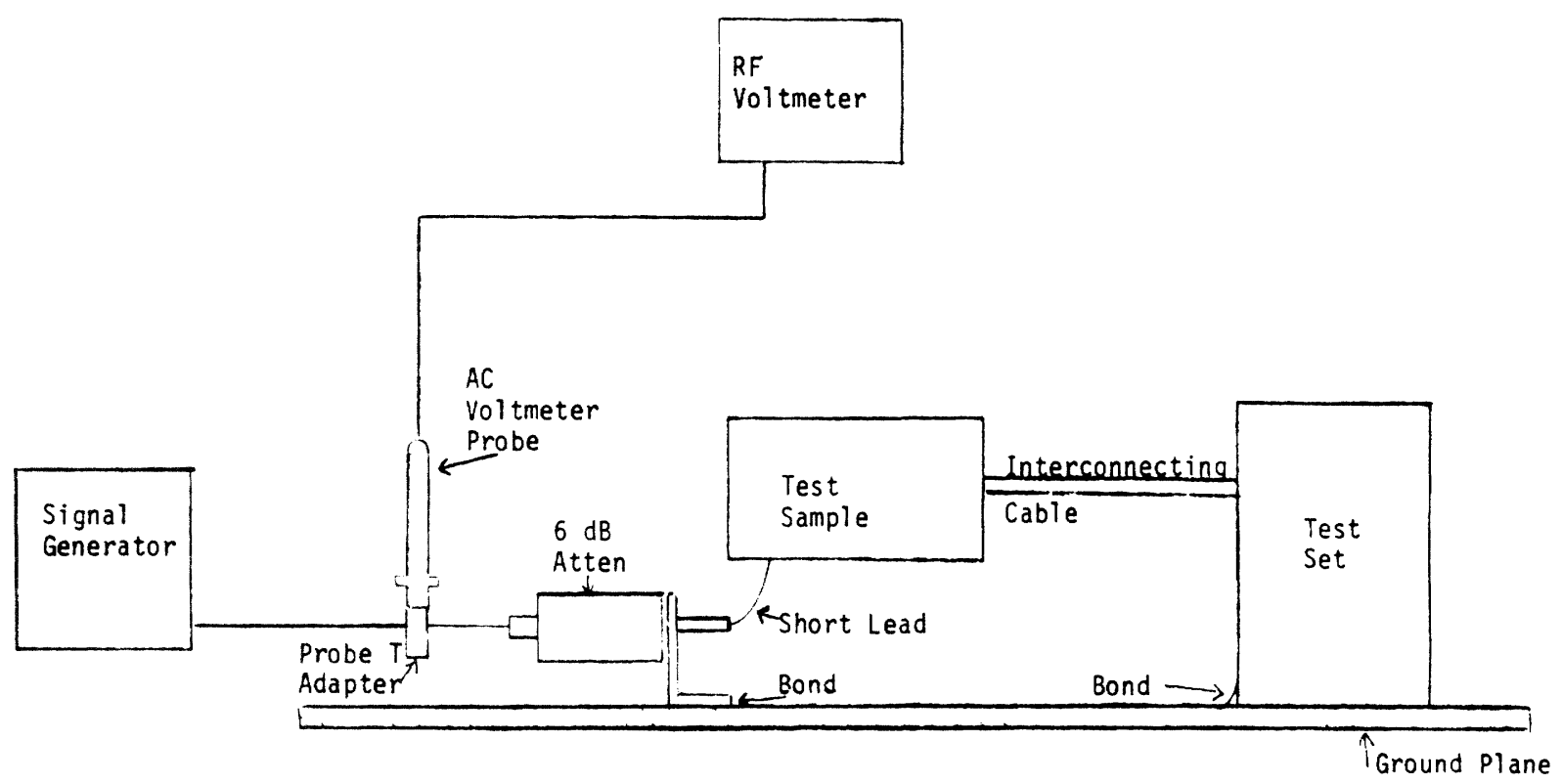

Ground Plane Interference Test Setup (0.05 to $100 \mathrm{MHz}$ )

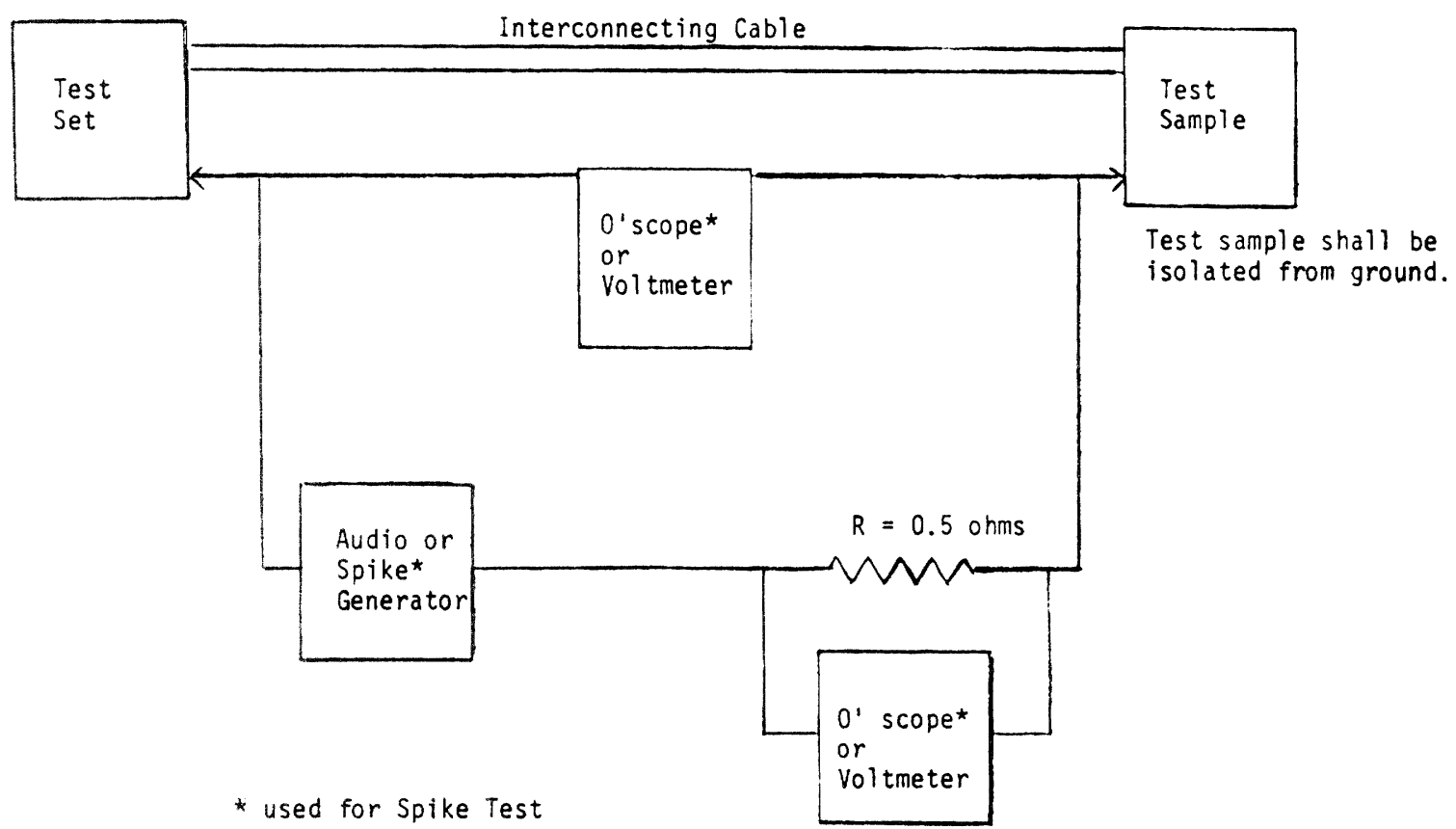

Ground Plane Interference Test Setup Spike Test and $320 \mathrm{~Hz}$ to $50 \mathrm{~Hz}$ Test

Figure 4.1 